\title{
VALUE OF 3-D USS OF PLACENTAL VOLUME, UTERINE AND UMBILICAL ARTERY DOPPLER IN PREDICTION OF PRE-ECLAMPSIA
}

\author{
By
Soha Farid Fahim Hassan, Abd El-Moneim Zakaria and Sameh Saeed Faraj

Department of Obstetrics and Gynecology, Faculty of Medicine, Al-Azhar University

Corresponding author: Soha Farid Fahim Hassan,

E-mail: soha_fahim@yahoo.com

\begin{abstract}
Background: Preeclampsia is a multisystem disorder of pregnancy defined by the combination of new-onset hypertension and proteinuria that contribute substantially to perinatal morbidity and mortality worldwide. Ultrasound can currently be used in the detection of adverse pregnancy outcome for example in Preeclampsia where Doppler indices and spectral wave forms are used.
\end{abstract}

Objective: To use Doppler ultrasound for evaluation on of placental volume changes using 3-D USS, as well as abnormalities in uterine and umbilical artery Doppler indices in prediction of pre-eclampsia.

Patients and Methods: This study was conducted in Department of Obstetrics and Gynecology of AlHussein Hospital, Al-Azhar University during the periods May 2016 till April 2017. This was a prospective observational study that carried on two hundred pregnant women enrolled into two equal groups. Group "A" consisted of 50 primipara and 50 multipara women with known risk factor to develop pre-eclampsia like previous history or medical disorder such as chronic hypertension and Group "B" consisted of 50 primipara and 50 multipara women without any risk factor to develop pre-eclampsia.

Results: There was no statistically significant difference between both groups as regard to umbilical artery pulsatility index (PI), while umbilical artery resistance index (RI) and abnormality have higher statistically significant values in group A. There was a statistically significant difference between both groups as regards uterine artery PI, RI, abnormality and persistent notch ( $\mathrm{p}$ value $=0.025,0.037,0.001$ and 0.001 respectively). There was statistically significant difference between PC and MG as regards to uterine artery abnormality and persistent notch. There was no statistically significant difference between both groups as regards to placental volume. ROC results revealed that umbilical artery RI, uterine RI, and placental volume cutoff values were higher than $0.67,0.56$, and 43 and the area under the ROC curve was equal to $0.672,0.851$ and 0.527. The sensitivity values of umbilical artery RI, uterine RI, and placental volume were 83.0, 86.5 and 79.2 respectively and the specificity values were $73.3,60.0$ and 62.5 respectively.

Conclusion: Three-dimensional Doppler ultrasound results, as well as resistance index from umbilical artery and uterine artery pulsatility index, resistance index, abnormality and persistent notch, could be considered as tools to determine hemodynamic repercussion caused by preeclampsia.

Keywords: Value of 3-D USS, Placental Volume, Uterine and Umbilical Artery Doppler, Pre-eclampsia.

\section{INTRODUCTION}

Pre-eclampsia (PE) is defined as a new onset of hypertension and proteinuria during pregnancy, after 20 weeks of gestation. It occurs in about $3-5 \%$ of pregnancies and causes substantial maternal and neonatal morbidity and mortality (Minire et al., 2013). Pre- 
eclampsia is thought to be caused by multiple factors, including placental ischemia, endothelial cell dysfunction, vasospasm, inflammation, improper angiogenesis and oxidative stress (Alves et al., 2018).

Many investigators believe that the placenta is the trigger for endothelial cell injury. Placental hypoperfusion or ischemia in preeclampsia has many causes. Preexisting vascular disorders such as hypertension and connective tissue disorders can result in poor placental circulation (O'Brien et al., 2013).

The ultrasonography is a non-invasive method that allows the study of several placental parameters since its formation. Through two-dimensional ultrasonography, the placenta can be assessed according to thickness and maturity (Nagpal et al., 2018). The threedimensional ultrasonography (3DUS) is one of the most recent technological advances in diagnostic medicine (Pomorski et al., 2012).

One of the applications of 3DUS is related to the vascularization assessment of organs and structures through threedimensional power Doppler (3DPD) (Pomorski et al., 2012). The 3D power Doppler allows the assessment of the architecture of the placental tree. Such information is very important considering that problems on the normal development of the placenta (Hata et al., 2011).

The shallow placentation noted in preeclampsia is a result of the inability of trophoblasts to invade the decidual vessels this invasion of the decidual arterioles is incomplete. The invasive cytotrophoblasts fail to replace tunica media, resulting in mostly intact arterioles that are capable of vasoconstriction. An abnormally elevated impedance to blood flow in the umbilical artery is an indirect reflection of placental pathology (Linask et al., 2014).

Currently, it is possible to assess women's risk to develop pre-eclampsia by performing uterine artery Doppler both in $1 \mathrm{st}$ and 2nd trimesters to investigate impaired trophoblastic invasion within spiral artery and hence impaired uterine flow (Scandiuzzi et al., 2016).

Determination of placental size is a part of overall assessment of intra-uterine environment. 3-D USS measurement of placental volume is a reliable index in cases of pre-eclampsia (Soongsatitanon and Phupong, 2019). In isolation, this form of screening is felt to be the most accurate as it can predict $81 \%$ of women with early onset pre-eclampsia (Thangaratinam et al., 2011).

This study was conducted to evaluate the placental volume changes using 3-D USS as well as abnormalities in uterine and umbilical artery Doppler indices in prediction of pre-eclampsia.

\section{PATIENTS AND METHODS}

This study was conducted in Department of Obstetrics and Gynecology of Al- Hussein Hospital Al-Azhar University during the periods May 2016 till April 2017. This a prospective observational study carried on two hundred pregnant women enrolled into two equal groups.

Group "A" consisted of 50 primipara and 50 multipara women with known risk factor to develop pre-eclampsia like 
previous history or medical disorder such as chronic hypertension.

Group "B" consisted of 50 primipara and 50 multipara women without any risk factor to develop pre-eclampsia.

Exclusion Criteria: Congenital fetal anomalies, presence of any other medical disorder with pregnancy and congenital placental or umbilical artery abnormalities.

Cases were subjected to 3-D USS to measure placental volume from $18-20$ weeks in addition to uterine artery and umbilical artery Doppler.

These parameters repeated on a fourweek basis until 34 weeks. The abnormality in Doppler and 3-D USS results were analyzed to detect its sensitivity in predicting occurrence of preeclampsia.

Pre-eclampsia was diagnosed if B.P equals or more than 140/90 detected in pregnant women after 20 weeks' gestation with appropriate cuff and supine position in at least two occasions 6 hours apart and random proteinuria equals or more than +1 .

All participating women underwent: History in details, physical examination, measuring of albumin level in urine and 3DPD ultrasound examination.

Ultrasounds were done for all cases including fetal biometry, placental morphology assessment and 3D Doppler ultrasound for uterine and umbilical artery. Each patient had a 3D power Doppler ultrasound exam. Automatic volume acquisition of the most vascular area of the placenta was obtained. The Virtual Organ Computer-aided Analysis (VOCAL) imaging was activated and histogram program was used to calculate vascularization index (VI), flow index (FI) and vascularization flow index (VFI) for all cases. Six steps measurements by the manual scanning around the area of interest and fastest scan quality. The same steps were done for all controls.

Upon participation or admission women were reminded of the study and written consents were obtained.

\section{Statistical analysis:}

Data were fed to the computer and analyzed using IBM SPSS software package version 20.0. (Armonk, NY: IBM Corp). Qualitative data were described using number and percent. Quantitative data were described using mean and standard deviation Comparisons between groups for categorical variables were assessed using Chi-square test. Student ttest was used to compare two groups. Friedman test was used to compare between more than two periods. Significance of the obtained results was judged at the 5\% level. Receiver operating curve (ROC) was used to determine the cutoff values of Umbilical Artery RI, Uterine RI, and Middle cerebral RI as predictors of PE. 


\section{RESULTS}

There was no statistically significant difference between both groups as regards maternal age, BMI and gestational age at birth. Group A showed that $36 \%$ of PG and $26 \%$ of $\mathrm{MG}$ developed $\mathrm{PIH}$, while group B showed that $4 \%$ of PG and $2 \%$ of MG with statistically significant difference between both groups (Table 1).

Table (1): Comparison between both group as regard to demographic data and PIH

\begin{tabular}{|c|c|c|c|c|c|c|c|}
\hline \multirow{2}{*}{ Proups } & \multicolumn{3}{|c|}{ Group A $(n=100)$} & \multicolumn{3}{|c|}{ Group B $(n=100)$} & \multirow[b]{2}{*}{$\mathbf{P p}_{1}$} \\
\hline & $\begin{array}{l}\text { PG }(n=50) \\
\text { Mean }+ \text { SD }\end{array}$ & $\begin{array}{l}\text { MG }(n=50) \\
\text { Mean } \pm \text { SD }\end{array}$ & P value & $\begin{array}{l}\text { PG }(n=50) \\
\text { Mean }+ \text { SD }\end{array}$ & $\begin{array}{l}\text { MG }(n=50) \\
\text { Mean } \pm \text { SD }\end{array}$ & $P$ value & \\
\hline $\begin{array}{l}\text { Maternal } \\
\text { age (year) }\end{array}$ & $25.41 \pm 4.28$ & $29.17 \pm 4.15$ & $<0.001^{*}$ & $23.25 \pm 2.38$ & $30.11 \pm 5.19$ & $<0.001$ & 0.284 \\
\hline $\begin{array}{l}\text { BMI } \\
(\mathrm{kg} / \mathrm{m} 2)\end{array}$ & $23.14 \pm 2.29$ & $25.18 \pm 4.16$ & $0.003^{*}$ & $23.72 \pm 2.54$ & $24.17 \pm 2.47$ & 0.371 & 0.608 \\
\hline $\begin{array}{l}\text { Gestational } \\
\text { age at birth } \\
\text { (wk) }\end{array}$ & $38.62 \pm 7.15$ & $37.16 \pm 5.37$ & 0.251 & $39.35 \pm 7.26$ & $39.62 \pm 5.81$ & 0.838 & 0.079 \\
\hline PIH No (\%) & $18(36 \%)$ & $13(26 \%)$ & 0.280 & $2(4 \%)$ & $1(2 \%)$ & 1.000 & $<0.001$ \\
\hline
\end{tabular}

Qualitative data were described using number and percent and was compared using Chi square test while quantitative data was expressed in mean $\pm \mathrm{SD}$

p: $p$ value for Student t-test for comparing between $P G$ and $M G$ in each group

p1: $p$ value for Student t-test for comparing between group A $(P G+M G)$ and group $B(P G+M G)$

Group A showed that $45 \%$ of patients have history of PE, $21 \%$ chronic HTN, $8 \%$ D.M, $4 \%$ kidney diseases, $16 \%$ obesity and $6 \%$ have other risk factors for PE (Table 2).

Table (2): Comparison between both groups as regard to risk factors of $\mathrm{PE}$

\begin{tabular}{|l|c|}
\hline Parameters $\quad$ Groups & $\begin{array}{c}\text { Group A (n=100) } \\
\text { No (\%) }\end{array}$ \\
\hline History of PE & $45(45 \%)$ \\
\hline Chronic Hypertension & $21(21 \%)$ \\
\hline D.M & $8(8 \%)$ \\
\hline Kidney diseases & $4(4 \%)$ \\
\hline Obesity & $16(16 \%)$ \\
\hline Others & $6(6 \%)$ \\
\hline
\end{tabular}

There was no statistically significant difference between both groups as regard to umbilical artery PI, while Umbilical Artery RI and abnormality have higher statistically significant values in group A. No significant difference was found between different periods in each group (Table 3). 
VALUE OF 3-D USS OF PLACENTAL VOLUME, UTERINE AND...

Table (3): Comparison between both groups as regards umbilical artery Doppler

\begin{tabular}{|c|c|c|c|c|c|c|c|}
\hline Groups & \multicolumn{3}{|c|}{ Group A $(n=100)$} & \multicolumn{3}{|c|}{ Group B $(n=100)$} & \multirow[b]{2}{*}{$\mathbf{p}_{1}$} \\
\hline $\begin{array}{l}\text { Umbilica } \\
\text { Artery }\end{array}$ & PG $(n=50)$ & $\begin{array}{c}\text { MG } \\
(n=50)\end{array}$ & $\mathbf{P}$ & PG $(n=50)$ & $\begin{array}{c}\text { MG } \\
(n=50)\end{array}$ & $\mathbf{P}$ & \\
\hline PI & \multicolumn{3}{|c|}{$1.29 \pm 0.71$} & \multicolumn{3}{|c|}{$1.12 \pm 0.55$} & 0.060 \\
\hline At 20 wk & $1.26 \pm 0.54$ & $1.24 \pm 0.61$ & 0.863 & $1.14 \pm 0.59$ & $1.16 \pm 0.62$ & 0.869 & \\
\hline At 24 wk & $1.29 \pm 0.72$ & $1.27 \pm 0.57$ & 0.879 & $1.12 \pm 0.45$ & $1.10 \pm 0.52$ & 0.837 & \\
\hline At 28 wk & $1.30 \pm 0.81$ & $1.28 \pm 0.38$ & 0.875 & $1.05 \pm 0.36$ & $1.08 \pm 0.28$ & 0.643 & \\
\hline At 32 wk & $1.33 \pm 0.78$ & $1.31 \pm 0.52$ & 0.880 & $0.962+0.17$ & $0.95 \overline{7}+0.31$ & 0.921 & \\
\hline Overall (PI) & $0.76 \pm 0.54$ & $1.28 \pm 0.52$ & 0.873 & $1.07+0.71$ & $1.07+0.52$ & 1.000 & \\
\hline $\mathbf{p}_{2}$ & \multicolumn{2}{|c|}{$>0.05$} & & \multicolumn{2}{|c|}{$>0.05$} & & \\
\hline RI & \multicolumn{3}{|c|}{$0.760 \pm 0.54$} & \multicolumn{3}{|c|}{$0.601 \pm 0.59$} & 0.048 \\
\hline At 20 wk & $0.743+0.48$ & $0.751+0.48$ & 0.934 & $0.724+0.64$ & $0.732+0.55$ & 0.947 & \\
\hline At 24 wk & $0.762+0.57$ & $0.767 \pm 0.57$ & 0.965 & $0.712+0.52$ & $0.718+0.78$ & 0.964 & \\
\hline At 28 wk & $0.775 \pm 0.63$ & $0.785 \pm 0.63$ & 0.937 & $0.652 \pm 0.41$ & $0.664 \underline{ \pm} 0.84$ & 0.928 & \\
\hline At 32 wk & $0.798+0.49$ & $0.791+0.49$ & 0.943 & $0.625+0.65$ & $0.637+0.71$ & 0.930 & \\
\hline Overall (RI) & $0.770 \pm 0.54$ & $0.774+0.58$ & 0.972 & $0.678+0.56$ & $0.688+0.72$ & 0.938 & \\
\hline $\mathbf{p}_{2}$ & \multicolumn{2}{|c|}{$>0.05$} & & \multicolumn{2}{|c|}{$>0.05$} & & \\
\hline $\begin{array}{l}\text { Abnormality } \\
\mathrm{N}(\%)\end{array}$ & $15(30 \%)$ & $11(22 \%)$ & 0.362 & $1(2 \%)$ & $0(0 \%)$ & 1.000 & $<0.001$ \\
\hline
\end{tabular}

Qualitative data were described using number and percent and was compared using Chi square test while quantitative data was expressed in mean $\pm \mathrm{SD}$

$\mathrm{p}$ : $\mathrm{p}$ value for Student $\mathrm{t}$-test for comparing between PG and MG in each group

$\mathrm{p} 1$ : $\mathrm{p}$ value for Student $\mathrm{t}$-test for comparing between group $\mathrm{A}(\mathrm{PG}+\mathrm{MG})$ and group $\mathrm{B}(\mathrm{PG}+\mathrm{MG})$

p2: $\mathrm{p}$ value for Friedman test for comparing between different periods in each group

There was statistically significant difference between groups as regard to uterine artery PI, RI, abnormality and persistent notch $(\mathrm{p}$ value $=0.025,0.037$, 0.001 and 0.001 respectively). Also, there is no statistically significant difference between $\mathrm{PC}$ and $\mathrm{MG}$ as regard to uterine artery abnormality and persistent notch.

No significant difference was found between different periods in each group (Table 4). 
SOHA FARID FAHIM et al.,

Table (4): Comparison between both groups as regard to uterine artery Doppler

\begin{tabular}{|c|c|c|c|c|c|c|c|}
\hline Groups & \multicolumn{3}{|c|}{ Group A $(n=100)$} & \multicolumn{3}{|c|}{ Group B $(n=100)$} & \multirow{2}{*}{$\mathbf{p}_{1}$} \\
\hline $\begin{array}{l}\text { Uterine } \\
\text { Artery }\end{array}$ & PG $(n=50)$ & MG $(n=50)$ & $\mathbf{P}$ & PG $(n=50)$ & MG (n=50) & $\mathbf{P}$ & \\
\hline PI & \multicolumn{3}{|c|}{$1.52 \pm 0.72$} & \multicolumn{3}{|c|}{$0.985 \pm 0.49$} & $<0.001$ \\
\hline At 20 wk & $1.65 \pm 0.52$ & $1.54 \pm 0.71$ & 0.379 & $1.37 \pm 0.29$ & $1.25 \pm 0.67$ & 0.248 & \\
\hline At 24 wk & $1.47 \pm 0.77$ & $1.67 \pm 0.37$ & 0.101 & $1.08 \pm 0.85$ & $0.96 \pm 0.55$ & 0.404 & \\
\hline At 28 wk & $1.55 \pm 0.56$ & $1.38 \pm 0.78$ & 0.214 & $0.85 \pm 0.16$ & $0.88 \pm 0.24$ & 0.464 & \\
\hline At 32 wk & $1.37 \pm 0.72$ & $1.51 \pm 0.92$ & 0.947 & $0.72 \pm 0.37$ & $0.75 \pm 0.37$ & 0.686 & \\
\hline Overall (PI) & $1.51 \pm 0.64$ & $1.53+0.70$ & 0.882 & $1.01 \pm 0.42$ & $0.96 \pm 0.46$ & 0.572 & \\
\hline $\mathbf{p}_{2}$ & \multicolumn{2}{|c|}{$>0.05$} & & \multicolumn{2}{|c|}{$>0.05$} & & \\
\hline RI & \multicolumn{3}{|c|}{$0.706 \pm 0.64$} & \multicolumn{3}{|c|}{$0.499 \pm 0.57$} & 0.016 \\
\hline At 20 wk & $0.675 \pm 0.68$ & $0.685 \pm 0.46$ & 0.931 & $0.554 \pm 0.34$ & $0.574 \pm 0.35$ & 0.773 & \\
\hline At 24 wk & $0.688 \pm 0.55$ & $0.710 \underline{ \pm} 0.59$ & 0.847 & $0.512 \pm 0.82$ & $0.497 \underline{ \pm} 0.28$ & 0.903 & \\
\hline At 28 wk & $0.712 \pm 0.83$ & $0.723 \pm 0.63$ & 0.941 & $0.482 \pm 0.71$ & $0.475 \pm 0.44$ & 0.953 & \\
\hline At 32 wk & $0.721+0.66$ & $0.733+0.39$ & 0.912 & $0.445+0.65$ & $0.452+0.51$ & 0.952 & \\
\hline Overall (RI) & $0.699 \pm 0.68$ & $0.713 \pm 0.52$ & 0.908 & $0.498 \pm 0.63$ & $0.500 \pm 0.40$ & 0.985 & \\
\hline $\mathbf{p}_{2}$ & \multicolumn{2}{|c|}{$>0.05$} & & \multicolumn{2}{|c|}{$>0.05$} & & \\
\hline $\begin{array}{l}\text { sAbnormality } \\
\mathrm{N}(\%)\end{array}$ & $12(24 \%)$ & $9(18 \%)$ & 0.461 & $0(0 \%)$ & $0(0 \%)$ & - & $<0.001$ \\
\hline $\begin{array}{l}\text { Persistent } \\
\text { notch }_{\mathrm{N}}(\%)\end{array}$ & $9(18 \%)$ & $5(10 \%)$ & 0.249 & $0(0 \%)$ & $0(0 \%)$ & - & $<0.001$ \\
\hline
\end{tabular}

Qualitative data were described using number and percent and was compared using Chi square test while quantitative data was expressed in mean $\pm \mathrm{SD}$

p: $p$ value for Student t-test for comparing between PG and MG in each group

p1: $p$ value for Student t-test for comparing between group A $(P G+M G)$ and group B $(P G+M G)$

p2: $p$ value for Friedman test for comparing between different periods in each group

There was no statistically significant difference between both groups as regards placental volume (Table 5). No significant difference was found between different periods in each group. 
Table (5): Comparison between both groups as regard to placental volume $($ Mean+SD)

\begin{tabular}{|c|c|c|c|c|c|c|c|}
\hline \multirow{2}{*}{ Groups } & \multicolumn{3}{|c|}{ Group A $(n=100)$} & \multicolumn{3}{|c|}{ Group B $(n=100)$} & \multirow{2}{*}{$\mathbf{p}_{1}$} \\
\hline & PG $(n=50)$ & MG $(n=50)$ & $\mathbf{P}$ & PG $(n=50)$ & MG $(n=50)$ & $\mathbf{P}$ & \\
\hline Placental volume & \multicolumn{3}{|c|}{$50.48 \pm 6.1$} & \multicolumn{3}{|c|}{$52.26 \pm 6.89$} & 0.054 \\
\hline At 20 wk & $37.28 \pm 4.18$ & $35.61 \pm 4.25$ & $0.049^{*}$ & $45.41 \pm 7.32$ & $43.27 \pm 7.16$ & 0.143 & \\
\hline At 24 wk & $42.34 \pm 3.92$ & $42.24 \pm 3.36$ & 0.891 & $48.91 \pm 5.16$ & $45.17 \pm 4.28$ & 0.001 & \\
\hline At 28 wk & $51.29 \pm 6.27$ & $50.63 \pm 6.71$ & 0.613 & $56.45 \pm 8.25$ & $54.35 \pm 7.63$ & 0.189 & \\
\hline At 32 wk & $55.41 \pm 6.35$ & $54.25 \pm 7.62$ & 0.410 & $62.81 \pm 7.32$ & $61.66 \pm 5.72$ & 0.384 & \\
\hline Overall & $46.58 \pm 5.18$ & $45.68 \pm 5.49$ & 0.401 & $53.40 \pm 7.01$ & $51.11 \pm 6.20$ & 0.087 & \\
\hline $\mathbf{p}_{2}$ & \multicolumn{2}{|c|}{$>0.05$} & & \multicolumn{2}{|c|}{$>0.05$} & & \\
\hline
\end{tabular}

Data was expressed in mean \pm SD

$\mathrm{p}$ : $\mathrm{p}$ value for Student t-test for comparing between $\mathrm{PG}$ and $\mathrm{MG}$ in each group

p1: $p$ value for Student t-test for comparing between group A (PG + MG) and group B $(P G+M G)$

$\mathrm{p} 2$ : $\mathrm{p}$ value for Friedman test for comparing between different periods in each group

Our ROC results revealed that Umbilical Artery RI, Uterine RI, and Placental volume cutoff values are higher than $0.67,0.56$, and 43 and the area under the ROC curve is equal to 0.672 , 0.851 and 0.527 . The sensitivity values of
Umbilical Artery RI, Uterine RI, and Placental volume were 83.0, 86.5 and 79.2 respectively and the specificity values were $73.3,60.0$ and 62.5 respectively (Table 6 and Fig. 1).

Table (6): Umbilical Artery RI, Uterine RI and Placental volume as predictors of PE

\begin{tabular}{|l|c|c|c|c|c|c|c|}
\hline $\begin{array}{c}\text { Test Result } \\
\text { Variable(s) }\end{array}$ & Cut off* & AUC & P-value & \multicolumn{2}{|c|}{ 95\% C. I. } & Sensitivity & Specificity \\
\hline Umbilical Artery RI & $\geq 0.67$ & 0.672 & 0.005 & 0.565 & 0.780 & 83.0 & 73.3 \\
\hline Uterine RI & $\geq 0.56$ & 0.851 & 0.001 & 0.772 & 0.924 & 86.5 & 60.0 \\
\hline Placental volume & $\leq 43$ & 0.527 & 0.175 & 0.436 & 0.641 & 79.2 & 62.5 \\
\hline
\end{tabular}

AUC: Area Under a Curve p value: Probability value CI: Confidence Intervals
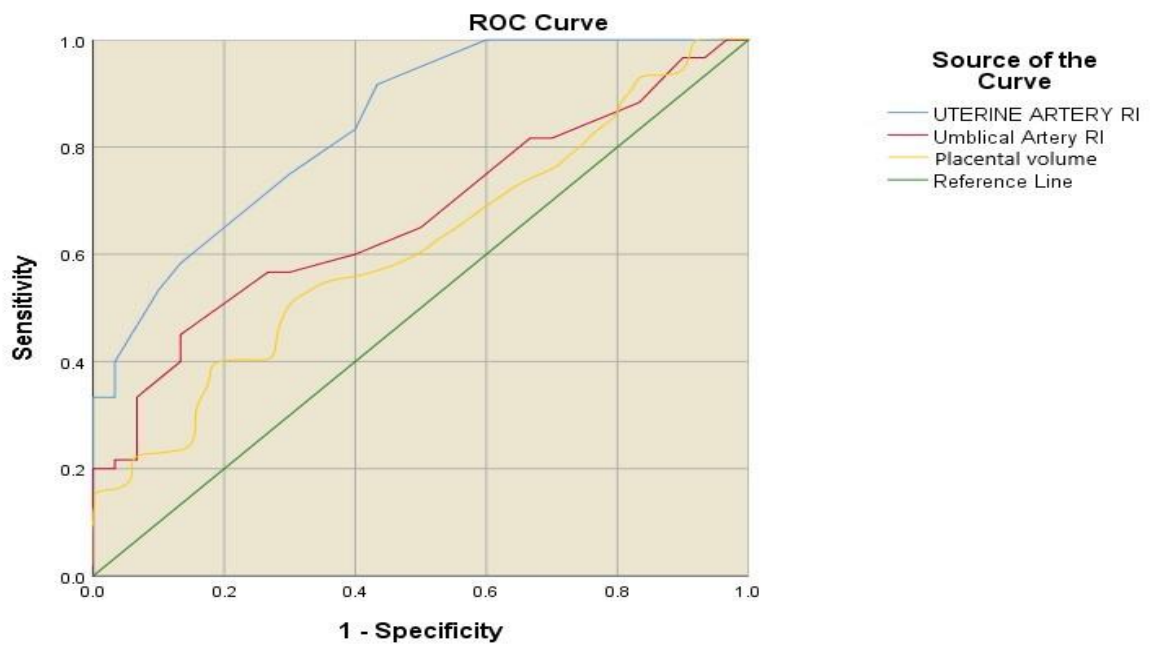


\section{SOHA FARID FAHIM et al.,}

\section{DISCUSSION}

In the present study, mean maternal age in primipara and multipara women with known risk factor to develop preeclampsia was $25.41 \pm 4.28$ and $29.17 \pm 4.15$ years respectively. While mean maternal age in primipara and multipara women without any risk factor to develop preeclampsia which was $23.25 \pm 2.38$ and $30.11 \pm 5.19$ years respectively, but with no noted statistically significant differences between both groups as regard maternal age. Furthermore, there was no statistically significant difference both groups as regard to BMI and gestational age at birth.

Hashish et al. (2015) conducted a prospective case control study including women with singleton pregnancies. Mean of age in Normal group was $26.8 \pm 6.4$ and High-risk group was $28.7 \pm 5.8$ with no statistically significant difference between both groups. Also, they did not find any statistically difference between groups as regard BMIs.

Adil et al. (2018) carried out a prospective observational study to evaluate the role of three dimensional power Doppler ultrasonography (3D PDUS) of the uteroplacental circulation in early pregnancy as a screening tool for prediction of preeclampsia. They reported that there is no statistically significant difference between pregnant females who developed preeclampsia and others who did not regarding age, BMI and gestational age.

Group A in our study showed that $45 \%$ of patients have history of PE, $21 \%$ chronic HTN, 8\% D.M, 4\% kidney diseases, $16 \%$ obesity and $6 \%$ have other risk factors for PE. Our study revealed
$36 \%$ of PG and 26\% of MG in Group A developed PIH, while group B showed that $4 \%$ of $\mathrm{PG}$ and $2 \%$ of MG with highly statistically significant difference between both groups.

Magee et al. (2014) reported that the incidence is higher in women with a history of preeclampsia, multiple gestations, chronic hypertension, and underlying renal disease. In addition, obesity, diabetes, thrombophilia, and age older than 40 years are risk factors that put a woman at an increased risk of developing preeclampsia.

Our study demonstrated there was no statistically significant difference between both groups as regards umbilical artery PI, while umbilical Artery RI and abnormality have highly statistically significant values in group A. The mean umbilical PI of pregnant women without PE was lower than the mean umbilical PI of women that developed PE. Furthermore, pregnant women who did not develop PE had lower mean umbilical RI than in women who developed PE RI. There was a statistically significant difference between groups as regard to uterine artery PI, RI, abnormality and persistent notch. In addition, there was a statistically significant difference between $\mathrm{PC}$ and $\mathrm{MG}$ as regard to uterine artery abnormality and persistent notch.

In corroborate to our results, de Almeida et al. (2014) published a prospective case-control study, Placental volumes and vascularity were evaluated by 3-dimensional sonographic, 3dimensional power Doppler histographic, and 2-dimensional color Doppler studies. Pregnant women were classified as normotensive or hypertensive and 
stratified by the nature of their hypertensive disorders. There was no statistical difference between these groups with regard to the PI in the umbilical arteries. However, a higher PI in both right and left uterine arteries was observed in hypertensive patients.

Also, Adekanmi et al. (2019) conducted a longitudinal cohort study, high-risk singleton pregnant women enroled between had uterine and umbilical artery Doppler sonography at 22-24 weeks and 32-34 weeks gestation.

The mean umbilical PI of pregnant women without PE was significantly lower than the mean umbilical PI of women that developed PE. Furthermore, pregnant women who did not develop PE had lower mean umbilical RI than in women who developed PE RI (Adekanmi et al., 2019).

Hashish et al. (2015) they stated that uterine artery RI and PI are significantly higher in the study group. Uterine artery PI is negatively correlated with placental volume and vascularization indices.

Mallikarjunappa et al. (2013) reported a significant association of preeclampsia and abnormalities of Doppler velocity waveforms in the umbilical, the uterine, and the middle cerebral arteries. This was also corroborated by Adekanmi et al. (2019).

The most frequently studied vessel to predict PE through Doppler US was the uterine artery, being representative of the condition of maternal vascular obstetric circulation. Some authors only focused on the uterine arteries to predict pregnancy complications. Harrington et al. reported results from a cross-sectional study of 191 pregnant women followed up at 24 weeks of gestation through analysis of Doppler US of uterine arteries waveforms (notching). The authors found abnormal uterine Doppler findings (including unior bilateral notching) in $110(57.6 \%)$ patients. They concluded that there is a clear link between high-resistance uterine waveforms (RI) and an increase in adverse outcomes of pregnancy, including preeclampsia. Papageorghiou and Leslie (2010) confirmed that those with increased mean PI have a six-fold rise likelihood of serious pregnancy complications.

Regarding to placental volume; we found that there was no statistically significant difference between both groups as regard to placental volume. They found that $\mathrm{PE}$ was seen in $7.7 \%, \mathrm{GH}$ in $9.0 \%$ and SGA in $8.0 \%$. Placental volume was not significantly different between the pregnancies with adverse outcomes and those without.

Similarly, de Almeida et al. (2014) reported that placental volumes were not statistically different among the different groups. However, patients with superimposed preeclampsia had a significantly lower placental volume-toestimated fetal weight ratio than normotensive pregnant women.

The performance of these tests was also compared using areas under receiver operator curves (AUC); Receiver operating curve (ROC) was used to determine the cutoff values of Umbilical Artery RI, Uterine RI, and Placental volume as predictors of PE. Our ROC results revealed that umbilical artery RI, uterine RI, and placental volume cutoff values were higher than $0.67,0.56$, and 43 
and the area under the ROC curve was equal to $0.672,0.851$ and 0.527 . The sensitivity values of Umbilical Artery RI, Uterine RI, and Placental volume were 83.0, 86.5 and 79.2 respectively and the specificity values were $73.3,60.0$ and 62.5 respectively.

Lopez-Mendez et al. (2013) reported that the general Doppler result had the most representative values with specificity and PPV of $75.7 \%$ and $78.6 \%$, respectively. The sensitivity and the NPV for the general US examination were calculated in $50.8 \%$ and $46.7 \%$, respectively.

The results of current study were also similar to those obtained by Odibo et al. (2011) who stated that the ROC curve for the prediction of PE was $0.71,0.69$ and 0.70 for VI, FI and VFI, respectively.

Dhakar and Naz (2017) reported that in umbilical artery Doppler sensitivity for all indices i.e. S/D ratio, RI and combined parameters were same. In umbilical artery Doppler RI had specificity of $93.68 \%$ and PPV of $25 \%$ and combination of parameters had specificity of $91.58 \%$ and PPV of $20 \%$. NPV of all the indices was found to be in range of $96-97 \%$. Thus, out of parameters of umbilical artery Doppler S/D ratio is considered to be best indicator.

\section{CONCLUSION}

Three-dimensional Doppler US result, as well as RI from umbilical artery, and uterine artery PI, RI, abnormality and persistent notch, may be considered as tools to determine hemodynamic repercussion caused by PE. Early recognition of women of preeclampsia can help in identifying high risk women who may benefit from early prophylaxis and enhanced surveillance.

\section{REFERENCES}

1. Adekanmi AJ, Roberts A, Akinmoladun JA and Adeyinka AO (2019): Uterine and umbilical artery doppler in women with preeclampsia and their pregnancy outcomes. Niger Postgrad Med J., 26:106-12.

2. Adil AS, Gamal El-Din MM, Farouk $O$ and Mohammed WE (2018): Efficiency of placental three dimentional power Doppler ultrasonography for predicting preeclampsia in early pregnancy. Egyptian Journal of Radiology and Nuclear Medicine, 49:892-898.

3. Alves NG, Motawe ZY, Yuan SY and Breslin JW (2018): Endothelial protrusions in junctional integrity and barrier function. Current Topics in Membranes, 82:93-140.

4. de Almeida E, de Paula C, Campos J and Fox $K$ (2014): Three-Dimensional Sonographic Assessment of Placental Volume and Vascularization in Pregnancies Complicated by Hypertensive Disorders. J Ultrasound Med., 33:483-491.

5. Dhakar V and Naz S (2017): Role of uterine and umbilical artery doppler assessment of the uteroplacental circulation in predicting preeclampsia: comparison between different doppler parameters. International Journal of Reproduction, Contraception, Obstetrics and Gynecology, 6:4314-18.

6. Hashish N, Hassan A and El-Semary A. (2015): Could 3D placental volume and perfusion indices measured at 11-14 weeks predict occurrence of preeclampsia in high-risk pregnant women? The journal of maternalfetal \& neonatal medicine: the official journal of the European Association of Perinatal Medicine, the Federation of Asia and Oceania Perinatal Societies. International Society of Perinatal Obstetricians, 28:1094-1098.

7. Hata $T$, Tanaka $H$, Noguchi $J$ and Hata $K$. (2011): Three-dimensional ultrasound evaluation of the placenta. Placenta, 32:105115 .

8. Linask KK, Han $M$ and Bravo-Valenzuela NJM (2014): Changes in vitelline and utero- 
placental hemodynamics: implications for cardiovascular development. Frontiers in Physiology, 5:390-93.

9. Lopez-mendez MA, Martinez-gaytan V, Cortes-flores $\mathbf{R}$ and Ramos-gonzalez RM (2013): Doppler ultrasound evaluation in preeclampsia. BMC Res Notes, 6:477-82.

10. Magee LA, Pels A and Helewa M. (2014): Diagnosis, evaluation, and management of the hypertensive disorders of pregnancy. Pregnancy Hypertension. An International Journal of Women's Cardiovascular Health, $4: 105-145$.

11. Mallikarjunappa B, Harish H, Ashish SR and Pukale RS (2013): Doppler changes in pre-eclampsia. Journal International Medical Sciences Academy, 26:215-216.

12. Minire A, Mirton M, Imri V, Lauren $M$ and Aferdita M. (2013): Maternal complications of preeclampsia. Med Arch., 67:339-341.

13. Nagpal K, Mittal P and Grover SB (2018): Role of Ultrasonographic Placental Thickness in Prediction of Fetal Outcome: A Prospective Indian Study. Journal of Obstetrics and Gynaecology of India, 68:349-354.

14. O'Brien E, Parati G and Stergiou G. (2013): European Society of Hypertension position paper on ambulatory blood pressure monitoring. Journal of Hypertension, 31:17311768.

15. Odibo AO, Goetzinger KR and Huster KM. (2011): Placental volume and vascular flow assessed by 3D power Doppler and adverse pregnancy outcomes. Placenta, 32:230-234.
16. Papageorghiou AT and Leslie K (2010): Uterine artery Doppler in the prediction of adverse pregnancy outcome. Current Opinion in Obstetrics and Gynecology, 19:103-109.

17. Pomorski M, Zimmer M, Florjanski J, Michniewicz J and Wiatrowski A (2012): Comparative analysis of placental vasculature and placental volume in normal and IUGR pregnancies with the use of three-dimensional Power Doppler. Archives of Gynecology and Obstetrics, 285:331-337.

18. Scandiuzzi RM, Prado CA de $\mathrm{C}$ and Araujo Júnior E. (2016): Maternal uterine artery Doppler in the first and second trimesters as screening method for hypertensive disorders and adverse perinatal outcomes in low-risk pregnancies. Obstetrics \& Gynecology Science, 59:347-356.

19.Soongsatitanon A and Phupong V (2019): First trimester 3D ultrasound placental volume for predicting preeclampsia and/or intrauterine growth restriction.. Journal of obstetrics and gynaecology. Journal of the Institute of Obstetrics and Gynaecology, 39:474-479.

20. Thangaratinam S, Langenveld J, Mol BW and Khan KS. (2011): Prediction and primary prevention of pre-eclampsia. Best Pract Res Clin Obstet Gynaecol., 25:419-33. 


\section{القيمة التببؤية للموجات فوق الصوتية ثلاثية الأبعاد لججم المشيمة و

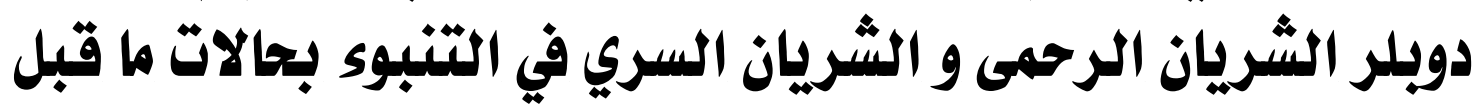 الإرتعاج}

سهى فريد فهيم حسن, عبد المنعم زكريا, سامح سعيد فاره قسم التوليد وأمراض النساء، كلية الطب (بنين), جامعة الأزهر

E-mail: soha_fahim@yahoo.com

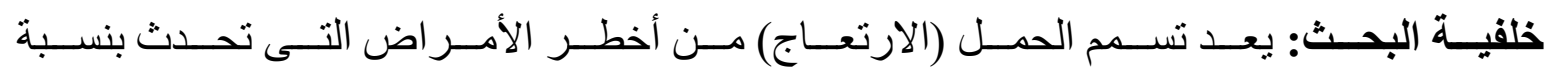

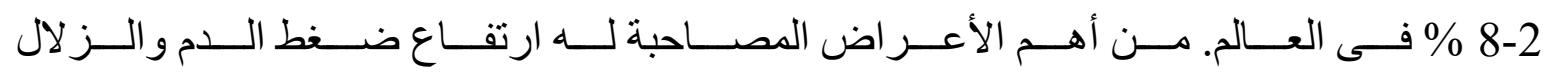

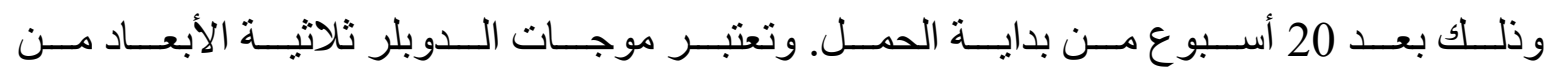

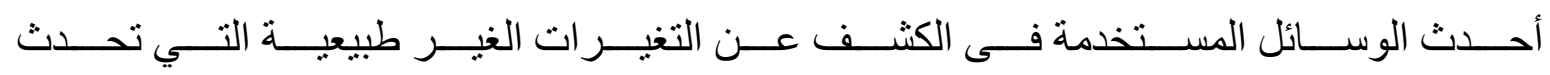

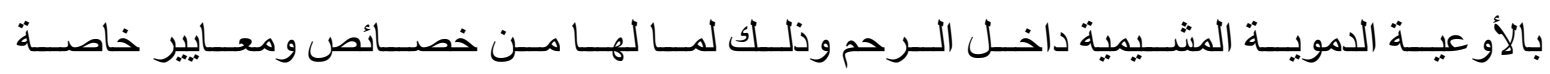

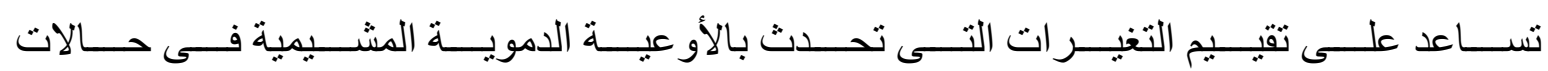
الارتعاج و المخاطر الناتجة عنها للأم والجنين على حد سواء.

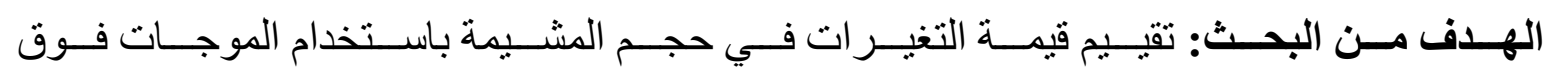

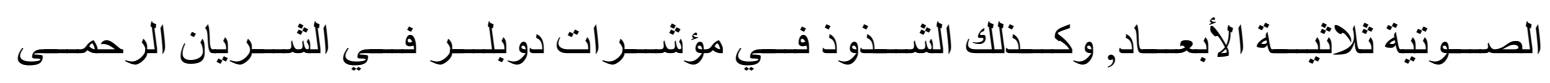
و الثريان السري في التنبوء بتسمع الحمل.

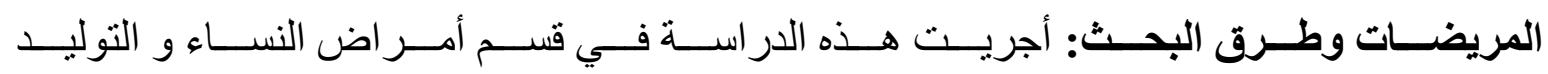

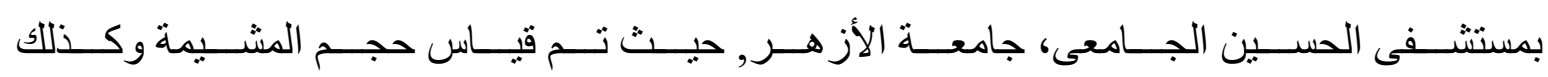

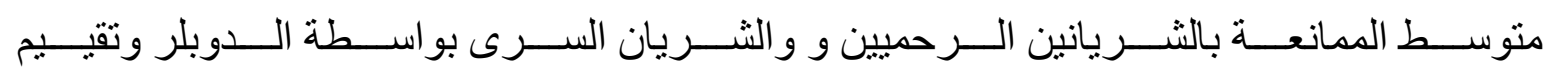

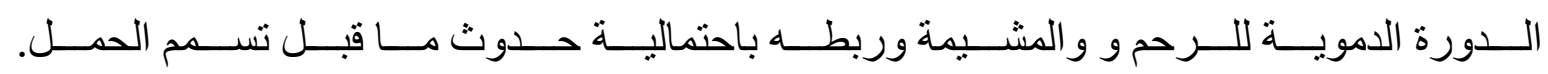

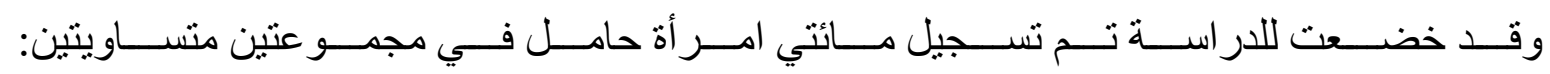

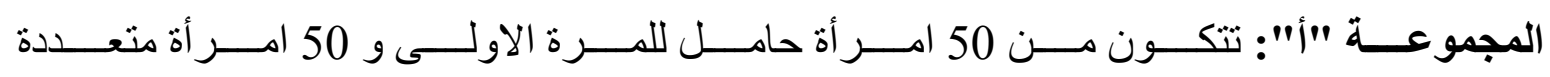

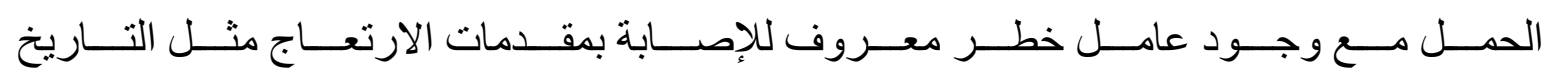

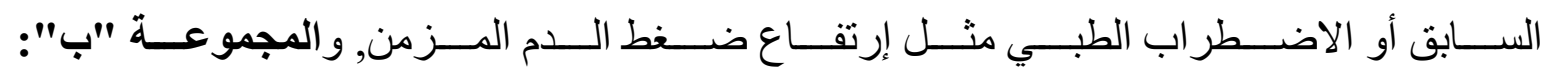

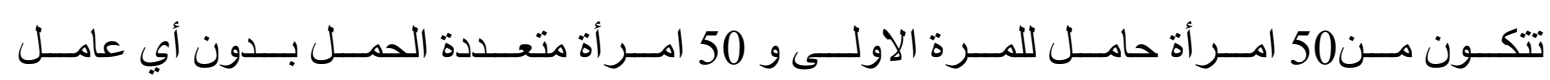
خطر للإصـابة بمقدمات الارتعاج. 


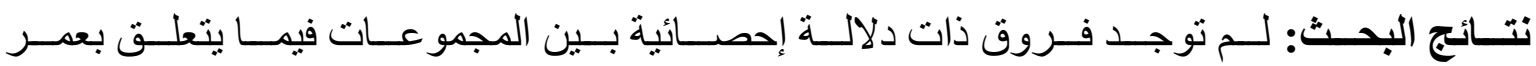

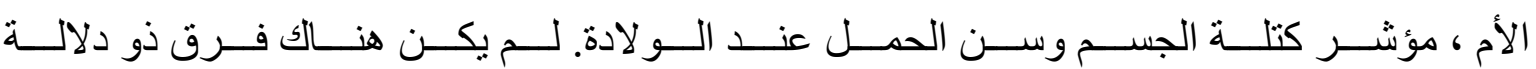

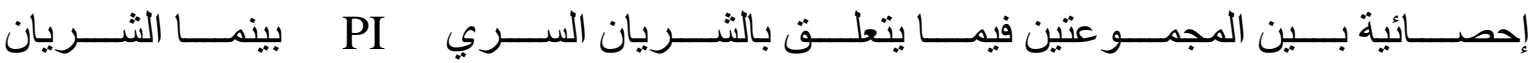

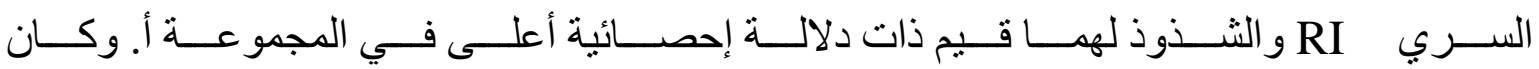

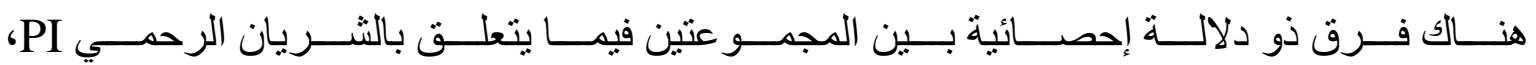

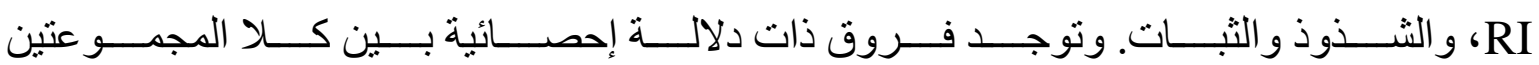

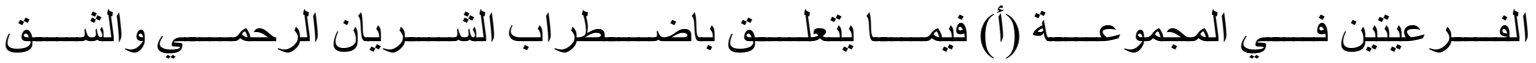

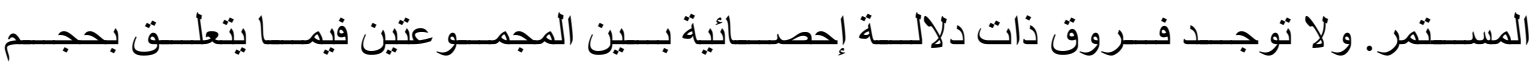

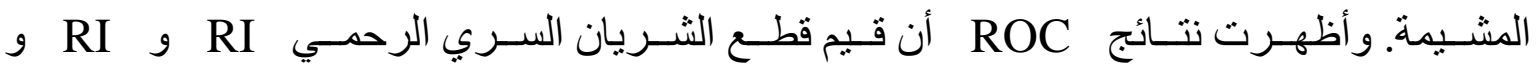

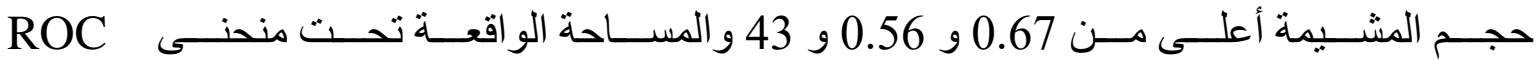

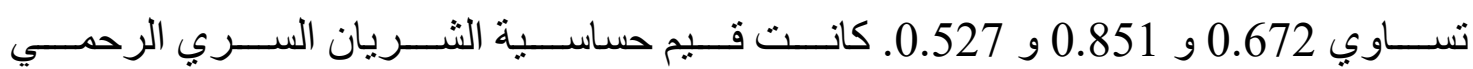

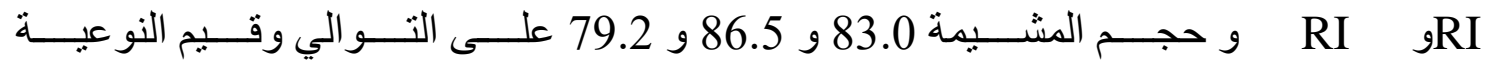
73.3 و 60.0 و 62.5 على التوالي.

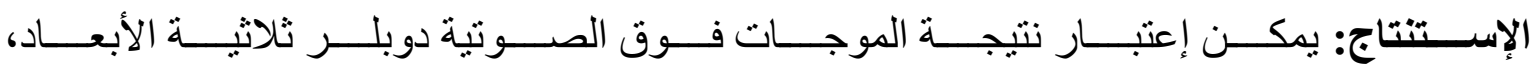

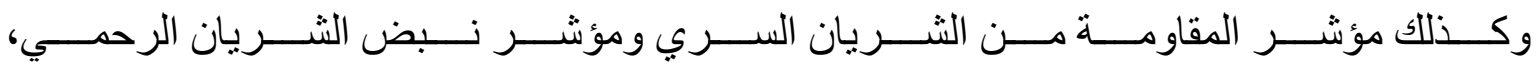

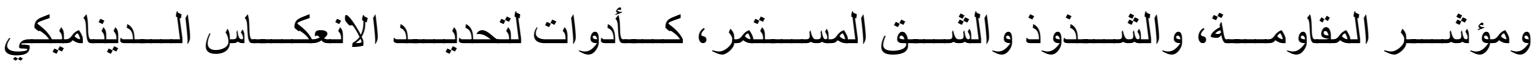
للاورة الناجم عن تسمم الحمل.

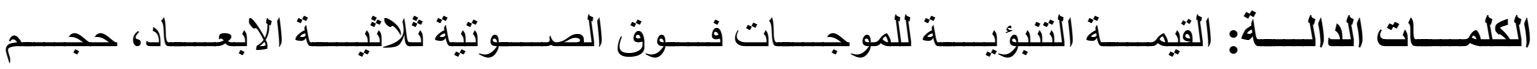
المشيمة، دوبلر الثريان الرحمى و الثريان السرى، ماقبل الارتعاج. 